Available online at: https://specedjournal.aspu.am/index.php/se

DOI: $10.24234 /$ se.v5i1.284

\title{
THE PERSPECTIVE OF SCHOOL-BASED OCCUPATIONAL THERAPY INTERVENTION TO ENHANCE THE PARTICIPATION OF LEARNERS WITH SPECIAL EDUCATIONAL NEEDS IN SCHOOL ACTIVITIES
}

\author{
AUTHORS' DATA \\ Zaruhi Harutyunyan, Ph.D. \\ Chair of Speech and rehabilitative therapy \\ Khachatur Abovyan Armenian State Pedagogical University, Republic of Armenia \\ Contacts: h.zaruhi@gmail.com \\ Gohar Hovyan, Ph.D. Associate professor \\ Chair of Speech and rehabilitative therapy \\ Khachatur Abovyan Armenian State Pedagogical University, Republic of Armenia \\ Contacts: gohar.hovyan@mail.ru
}

\begin{abstract}
The aim of this study was to investigate the participation problems in school activities of the learners with special educational needs in order to establish the possible ways of Occupational Therapy intervention in school settings in Armenia. In total 111 learners with special educational needs were observed and their participation in educational and noneducational activities was assessed using the "Occupational Therapy School Skills Assessment" tool. Since the educational environment considered being crucial for the learners' participation, the school environment was observed to determine the features facilitating or burdening their involvement in all kinds of school activities.
\end{abstract}

Quantitative research methodology was used to outline and summarize the participation problems of learners with special educational needs for establishing the possible ways of Occupational Therapy intervention.

The results of this study highlighted that in the inclusive school in Armenia the learners with special educational needs still had participation restriction and their involvement in educational and non-educational activities was limited due to lack of individual skills and abilities, as well as not adapted environmental conditions. Learners with physical dysfunctions (62\%) experienced mobility problems and had significant difficulties performing self-care activities, about $65 \%$ were not able to take part in outdoor events, permanent support and assistance were required. For the learners with autistic spectrum disorder (50\%) communication 
with peers and staff members was still challenging and participation in the educational process was not effective.

Keywords: inclusive education, learners with special educational needs, school activity, participation, environment, occupational therapy.

\section{INTRODUCTION}

In educational process given assistance to the learners with special educational needs (SEN) assumes the provision of "appropriate" support based on the assessment of the limitations and problem-based "needs", using the specific knowledge, skills and attitude (UNESCO, 1994; "United Nations Convention on the Rights of Persons with Disabilities," 2006). Although the integration and education of learners with SEN in inclusive schools in Armenia have been organized in a special direction, however, scientific research conducted during the period of the 2006-2014 year proved that the process of inclusion of these learners was not fully in line with the use of appropriate social and rehabilitation methods (Harutyunyan, 2014; Saratikyan, 2013). The results of surveys and the study of complex approaches of Occupational Therapy intervention provided to learners with SEN showed that the organization of inclusive education was not sufficient and there were still obvious problems that hinder the independent and effective participation in school activities.

Taking into account that the organization of inclusive education requires comprehensive social and rehabilitation methods, using a combination of different professional approaches, the role of Occupational Therapy intervention is considered to be important and significant which was aimed at improving the learner's participation in educational activity, and ensuring their full involvement in the educational process (Hemmingsson, Borell, Gustavsson, 2003). It is well known that successful implementation of inclusive education for learners with SEN and enhancement of their participation in educational and school activities mainly based on the comprehensive assessment of individual abilities, capabilities, interests and needs as well as the evaluation of environmental conditions (Cohn, \& Lew, 2010). Particularly, Occupational Therapy intervention in schools is intended to help the learners with SEN to develop educational and functional skills for everyday life in the areas of selfcare, life skills, school work and play.

Therefore, the aim of this study is to investigate the participation problems in school activities of learners with special educational needs in order to establish the possible ways of Occupational Therapy intervention in school settings in Armenia. 


\section{LITERATURE REVIEW}

Education as a fundamental human right (according to the Universal Declaration of Human Rights, United Nations, 1948) defines the educational right of every child, regardless of any restrictions. At the same time, it excludes the provision of segregated education, viewing it as a violation of the right of learners to appropriate inclusive education, limiting their access to further education. Being philosophical and the combination of pedagogical experience, inclusive education contributes to the educational development of each student to be involved in the system, to be respected, protected, to feel confident in one's own potential in the process (Haug, 2017). In this regard, inclusive education contributed to the process of involving each learner in the educational system, respecting, protecting and feeling confident in their own potential (Harutyunyan, Hovyan, Harutyunyan, 2018). At the same time, inclusive education being based on the principles of fundamental human rights, beliefs and values, promotes the social involvement of each learner in society, supports active participation in the educational process, and contributes to the formation of positive relationships between learners with SEN and their peers in the school environment (Ainscow, 1999).

Since 2014 with the adoption of the RA Law on making amendments to the Law of the Republic of Armenia "On Education" Armenia fixed the political will to transition to the General Inclusive Education. "The Republic of Armenia declares General Inclusive Education as a guarantee of ensuring the right to education of every child." In February 2016, the government approved the "Action Plan and Schedule for the Implementation of the General Inclusive Education System", according to which the process would start in 2016 and end in 2021 (Government of RA, 2016, February 18, Resolution No. 6). The strategic aims of the General Inclusive Education were defined in terms of quality of education and accessibility, which comprised the following:

1) Expanding the opportunities for organizing the education of learners with SEN in secondary schools, moving to a system of General Inclusive education.

2) Introduction of effective mechanisms for identifying, assessing and organizing the education of learners with SEN.

3) Investment of the pedagogical-psychological support services.

Inclusive education practice has shown that multidisciplinary teamwork provides an opportunity to assess each learner's educational needs from their own professional perspective while addressing their health and social needs that have a significant impact on the learner's education (Harutyunyan, Hovyan, 2013). However, the active participation of each learner in the school activities was conditioned by the peculiarities of his/her physical-mental development, taking into 
account the current and nearest development zones (Luria, and Vygotski, 1965), the educational needs in order to ensure the efficiency of inclusive education (Reid, et. al., 2006). For a more efficient and complete organization of this process, it was necessary to pay special attention to the mutually agreed work of the multidisciplinary team, including different specialists in the field of pedagogy and rehabilitation (Starczewska, Hodkinson, and Adams, 2012). Thus, as a result of a comprehensive assessment and analysis of the needs of learners with SEN, it was only possible to ensure their involvement in the educational process, to develop his/her learning skills and ability to integrate into public life and to become a full member of society in the future (Armstrong, 2012; Bernal, 2009).

Education, which is the learner's primary objective also has been identified by the American Occupational Therapy Association (AOTA) as one of the key performance areas; it refers to the "activities needed for learning and participating in the educational environment" (American Occupational Therapy Association, 2014, p. S20). From this perspective, the occupation of education includes academic (e.g., math, reading, writing), non-academic (e.g., sports, self-care, outdoor events), and prevocational and vocational activities. Since participation in the educational process and in everyday occupations is beneficial for learners' development, health, and well-being (WFOT, 2016; Law, 2002), Occupational Therapy has an important role in the school environment.

Mann et al., (2015) defined that learning or academic performance was a complex multifactorial process that involves demonstrating knowledge, paying attention to instruction, accessing the learning environment and educational materials, and working collaboratively with peers. Accordingly, poor academic performance has been associated with an increased risk of dropping out of school and obtaining poor postsecondary outcomes. Within the multidisciplinary teamwork maintaining a "client-centered" approach occupational therapy expanded the involvement of learners with SEN in the activities of their choice that they want to engage in or that they want to perform (Sayers, 2008). Best practice in school-based occupational therapy emphasize the importance of working collaboratively with school staff, teachers and parents to modify the context and the occupation and to provide occupational strategies to enhance the performance and participation of children in the school environment ( Bazyk and Cahill, 2015). It has been already approved that assessment of learner's individual abilities was the first step in the Occupational Therapy intervention process, which was the most important precondition for the organization of inclusive education and ensure the effective involvement of learners with SEN in the educational process based on "childcentered" pedagogy (Agran, Blanchard, \& Wehmeyer, 2000).

"Occupation-based evaluation approaches helped the multidisciplinary team make decisions about the learner's ability to participate and perform in the school setting and identify the ways that the disability affects the student's participation in school activities and routines" (Polichino, 2001, p. 
35). For this reason, diverse occupational therapy assessment methods were used to focuses on strengths and weaknesses in educationally relevant occupational performance areas, to understand the learner's interests and preferences, to gain important information about his/her social participation, as well as his or her habits and routines. Access to an educational environment is crucial to the equal participation and full inclusion for every learner. School-based occupational therapy intervention ensured the effectiveness of learner's participation in the school environment which includes the classrooms, cafeteria, playgrounds, restrooms, gymnasium, and other spaces (Rens \& Joosten, 2014).

For this reason, the aim of this quantitative study was to investigate the participation problems in school activities of learners with special educational needs in order to establish the possible ways of Occupational Therapy intervention in school settings in Armenia.

\section{METHODOLOGY}

This study used a quantitative research design, to assess and collect data on the degree of participation in the educational process, the involvement in non-educational activities and independent participation in self-care activities of 111 learners with SEN from 20 schools. The use of the quantitative method made it possible to identify the basic problems of learners with SEN while taking part in school activities that assume educational and non-educational activities and the results have been presented by means of mathematical-statistical calculations. The current study was constructed on activity-based assessment and "Occupational Therapy School Skills Assessment" tool to identify specific challenges of learners in school environments, identify school-based occupational therapy interventions directions and establish guidelines for increasing learners' participation. The "Occupational Therapy School Skills Assessment" tool was translated into Armenian, tested, and adapted taking into account local and cultural specifics.

\section{PARTICIPANTS}

For this study in total 111 learners with special educational needs have been observed from 20 inclusive schools in Armenia and their participation in educational and non-educational activities had been examined in order to find out the main problems and difficulties of their participation in school activities. During the study period, the representation of the participants in 20 inclusive schools included the following categories:

1. 38 learners from $4-5$ grade having physical dysfunction and musculoskeletal disorders: (difficulty in walking, posture, movement, fine motor skills, controlling the movements).

2. 44 learners from 6-8 grade having autistic spectrum disorder. 
3. 29 learners with Attention Deficit Hyperactivity Disorder.

\section{DATA COLLECTION}

Data was collected using activity-based assessment and the "Occupational Therapy School Skills Assessment" tool to define learners' participation problems in educational activities, the performance of self-care skills, as well as their involvement in non-educational activities, was determined. In the data collection process special attention was given to the assessment of the following aspects:

- Functional skills of the learners with SEN, such as functional mobility (transfer) in the school environment.

- Involvement in educational activities; writing skills.

- Performance of self-care skills at school (participating in activities in the canteen, toilet or other places inside the school).

- Compliance of the educational environment to the needs of the learners with SEN.

In line with activity-based assessment and evaluation, the potential ways and main areas of occupational therapy intervention have justified making the teaching of learners with SEN more effective and focused on their abilities, needs and preferences (Fisher, \& Jones, 2014). Since participation in any kind of activity is highly influenced by the environmental condition that can facilitate or make it challenging, in this study school environment appropriateness to the needs of the learners with SEN has been assessed.

\section{DATA ANALYSIS}

The data analysis was carried out according to quantitative methodology. The questions of the survey used for this study were of closed-ended multiple-choice format. For analysis, quantitative data were downloaded into a Microsoft Excel spreadsheet and organized by data type and content. The closed-ended questions were analyzed using descriptive statistical analyses, more specifically by calculating percentages and data frequencies. The open-ended questions, which included handwriting, the observation of school environment were coded according to the relevant categories, grouped, and presented in numerical percentage (Yadov, 2007). 


\section{RESULTS AND DISCUSSION}

The results of collected data analysis gave an opportunity to identify the main barriers and difficulties of participation in the educational process of learners with SEN that limit their involvement in the educational and non-educational activities, as well as performing self-care at school. The main challenging areas of participation in the school environment had been identified and assessed according to the participants' abilities and environmental possibilities. The results of the conducted assessment in three groups of learners with SEN have been categorized, grouped, and presented in numerical percentages.

\section{Difficulties in performing functional mobility at school.}

Since in the process of classroom activity participation it was important for the learners to be able to move independently, and perform varied activities, the functional mobility skills of the learners with SEN (approaching the blackboard, moving around the school, managing posture), difficulties and the environmental conditions were studied.

As a result of functional mobility assessment, several issues have been identified that make it difficult for the learners to participate effectively in the learning process. Learners with SEN experienced restrictions on the use of the bathroom, gym, canteen due to unfavourable environmental conditions. They had difficulty managing posture and sitting positions due to an uncomfortable wheelchair or an uncomfortable school desk. Also due to the lack of elevators or ramps inside the school, lessons were organized only on the first floor.

The identified core difficulties in performing functional mobility in the school environment were approaching and writing on the blackboard, being able to move around the school and going up/down the stairs.

According to the results of the assessment, it was possible to state that most of the learners with physical dysfunctions and musculoskeletal disorders (51\%) were not able to approach the blackboard on their own both due to limited individual and physical skills (motor skills, movement skills, difficulty maintaining balance, difficulty controlling posture), as well as the presence of uncomfortable environmental conditions. The vast majority of them $(62 \%)$ were not able to move around the school at all, from one place to another, to the toilet, to go upstairs, and so on. Research showed that these children were helped by classmates and parents, but mostly, they only attend classes on the ground floor. Only small percentage of the learners with SEN (16\%) were able to go up the stairs on their own, $41 \%$ did it with the help of classmates, staff members or teachers, and the rest of the respondents (43\%) had difficulties, was not able to do the above-mentioned activities on their own (Figure 1). 


\section{Figure 1.}

\section{Functional mobility assessment of the learners having physical dysfunction.}

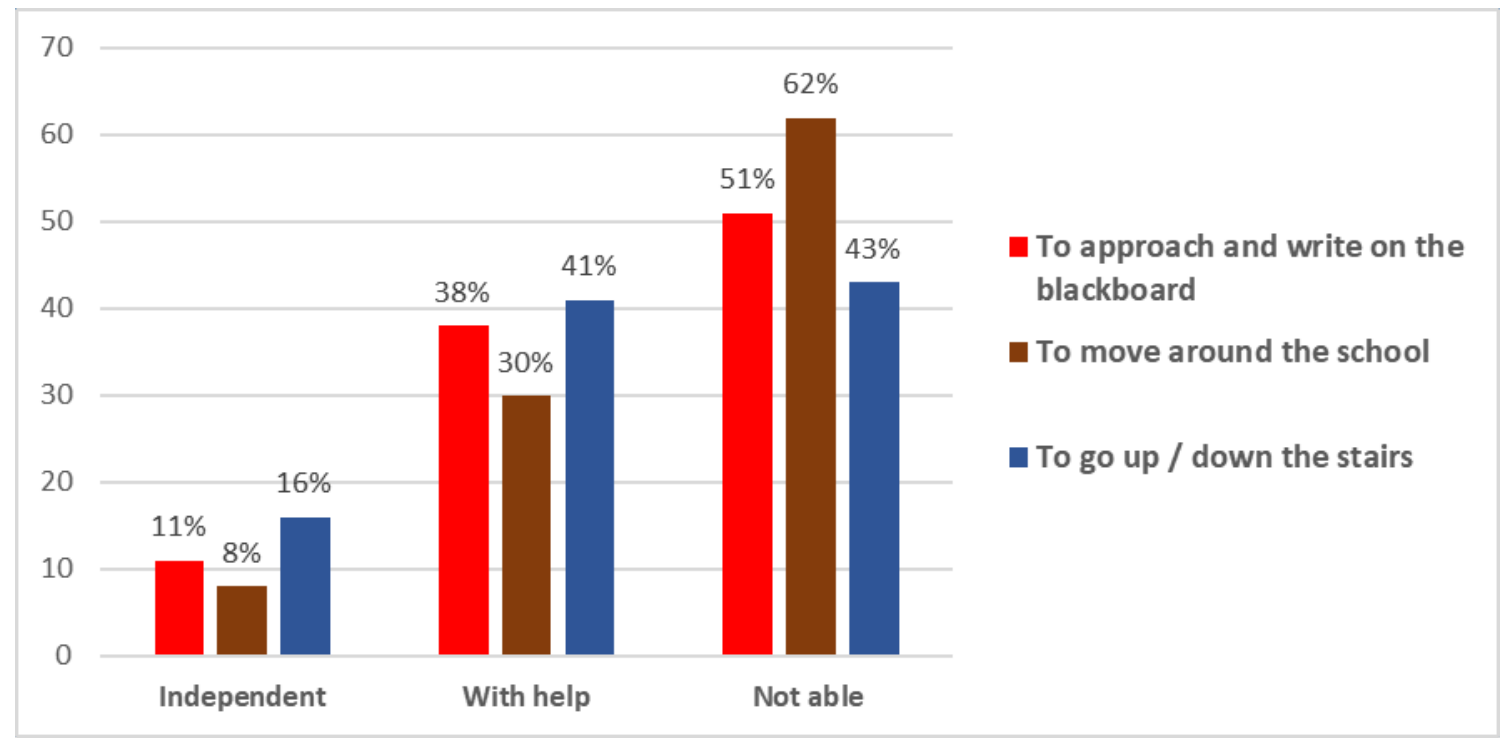

The results indicated that although the communication skills of learners with physical dysfunctions were sufficiently developed, there was still some limitation in their social participation and interaction with classmates, which was reflected in passivity in the classroom, not taking part in outdoor activities. Also, not supportive and reachable physical environment can lead to mobility difficulties and inability to perform daily occupations and can impair the development of normal posture reactions (Case-Smith, 2015).

It should be noted that with sufficient support and specialized intervention it was possible to develop necessary skills and support learners with physical dysfunctions to master their abilities and achieve independence in movements and actions. Occupational therapy based assessment and intervention could be appropriate for defining the level of required external support (adjusted chair, devices for holding the sitting position, accessories for posture deviations) that would ensure movement performance and could have an impact on the quality of performance of learners with SEN (Kardos, Prudhomme White, 2005).

The results of the study of the functional mobility assessment of the learners with autistic spectrum disorder showed that despite the absence of mobility disorders or problems, there was still recorded a low level of independent participation in school activities. Thus, only a part of the respondents (27\%) was able to approach the blackboard and write on their own, while the others $(39 \%)$ had difficulties in performing this activity due to both cognitive and 
behavioural problems. The majority of respondents (75\%) were able to go up/down the stairs by themselves, but only $43 \%$ were able to move independently at the school environment.

Examining the functional mobility of learners with attention deficit hyperactivity disorder (ADHD), it became clear that, especially in the classroom, they had a variety of problems that manifest themselves with difficulty concentrating on a task, resulting in an inability to complete written assignments (Figure 2). The research showed that only $41 \%$ were able to approach and write on the blackboard independently, even though they were aware of the teacher's requirements and had completed the tasks. The rest of the participants from this group $(21 \%)$ had difficulty performing and responding to simple verbal instructions, for example, "Come to the blackboard, write the date, take the chalk," etc. The majority of the respondents from this group were able to go up/down to stairs (90\%), and about $69 \%$ were able to move on their own at school. However, some of the respondents (17\%) needed help to move around in the school environment.

\section{Figure 2.}

\section{Functional mobility assessment of the learners with ADHD.}

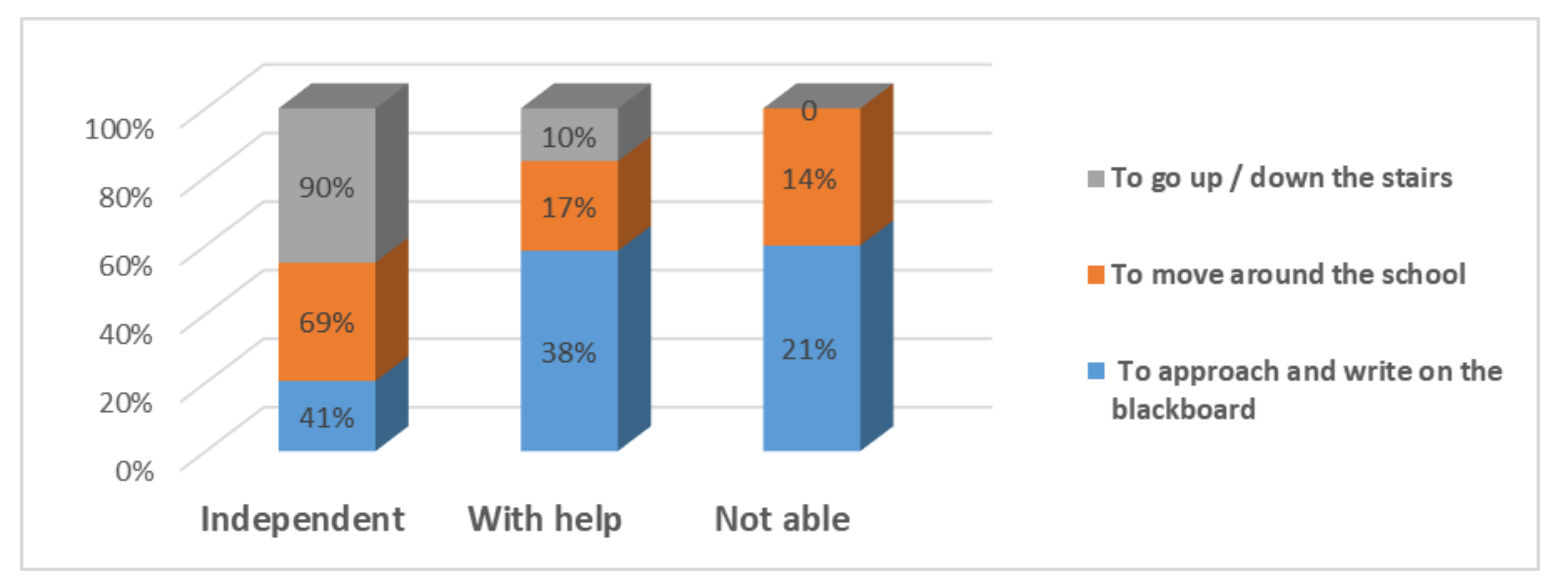

\section{Involvement in educational and non-educational activities}

\section{a. Assessment of writing skills}

In order to assess the factors that facilitate and hinder the writing process of learners having physical dysfunction, the lesson processes were observed, as well as their skills and concentration, transcription, dictation, and writing on the blackboard abilities were evaluated. During the evaluation, both the individual abilities and the environmental conditions of the schools providing inclusive education were taken into account, as well as provided support level by the teaching staff was determined. Studies have shown that for most learners in wheelchairs, it was difficult to approach and write on the blackboard, as there were a number of 
environmental barriers: rows were too narrow to move around in a wheelchair; the height of the blackboard did not correspond to the height of the child in the wheelchair; many teachers did not encourage them to write on the blackboard.

However, the learners with physical dysfunction (without limitation in the upper extremity, having mild mobility problems) were able to complete the given assignment, follow the oral instructions, to focus on the given task. However, most of the learners from this group (24\%) had attention concentration difficulty, about 32\% (especially having muscle tension and difficulty in moving) were unable to make transcripts and dictations, while the others (38\%) were not even able to perform any action related to fine motor skills - to hold a pen, to perform controllable and targeted movements (Figure 3).

\section{Figure 3.}

\section{Assessment of writing skills of learners having physical dysfunction.}

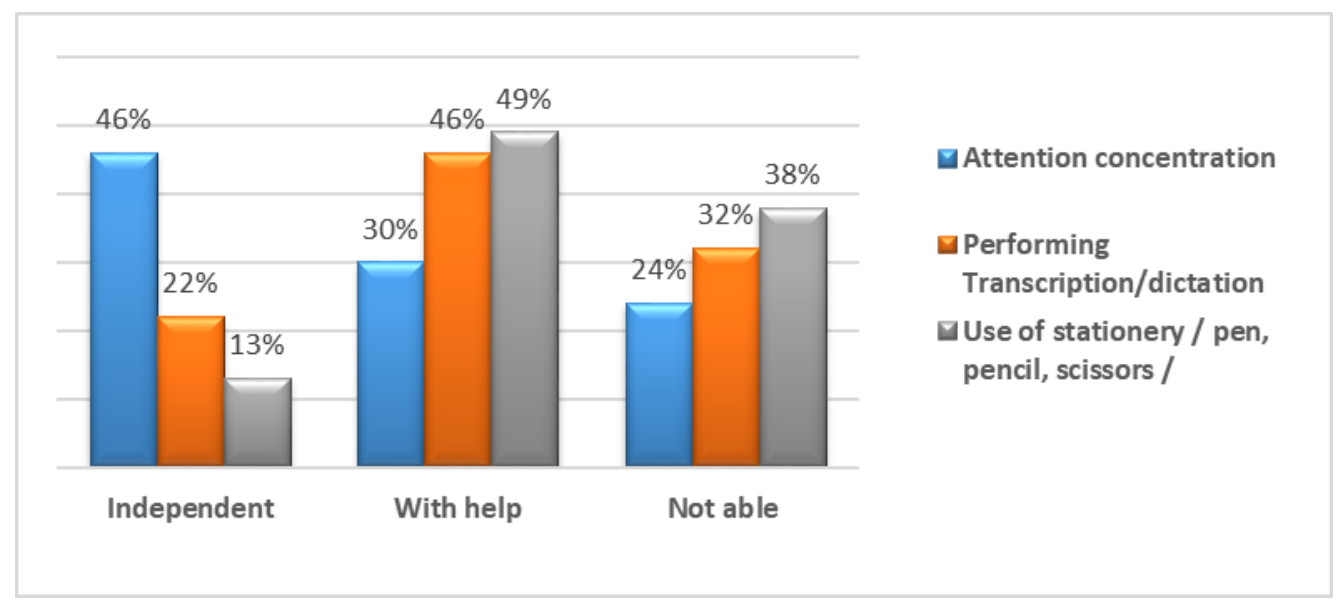

During the observations, it became clear that learners with SEN mainly used ordinary stationery or did not use it at all because they were uncomfortable. However, personally adapted stationery and special training on usage improved learners' independent performance and participation in the writing process (Schneck, \& Amundson, 2010).

Many studies have demonstrated that handwriting interventions were successful at improving handwriting skills in children (Case-Smith, Holland, Lane, \& White, 2012; CaseSmith, Weaver, \& Holland, 2014; Howe, Roston, Sheu, \& Hinojosa, 2013), as visual-motor, visual-perception, in-hand manipulation, and handwriting legibility represented the core skills for participating in educational and daily activities (Mackay, McCluskey, \& Mayes, 2010). Therefore, in-depth occupation-based assessment and study of such skills make it possible to identify the difficulties and conduct school-based occupational therapy (Hoy, Egan, \& Feder, 2011). 
Learners with autistic spectrum disorder were able to perform writing skills and use stationery (52\%), about $32 \%$ of them showed difficulties and the effectiveness of the writing was directly related to the problems of concentration, and a number of obstacles in the classroom (noise, inappropriate teaching's methods and approaches, etc.). For learners with ADHD difficulties of the writing process were mainly due to their behavioral manifestations, as a result of which they find it difficult to focus on the written work, perform controlled movements, although they had developed fine motor skills, and were able to use stationery as intended.

\section{b. Communication and participation in non-educational activities}

In order to identify the level of communication and involvement of learners with SEN in non-educational activities, and out-of-school events, the following tasks among the research participants had been assessed:

- Communicating with classmates and the teachers.

- Asking for help if needed, express wishes.

- Participating in games, out-of-school events.

According to the research results, participation in non-educational activities and out-ofschool events among these three groups of recipients was very restricted and independent participation made up a small percentage (Table 1).

\section{Table 1.}

\section{Participation in activities.}

\begin{tabular}{|c|c|c|c|}
\hline & $\begin{array}{l}\text { I group } \\
\text { Learners having physical } \\
\text { dysfunction and } \\
\text { musculoskeletal disorders } \\
(\mathrm{n}=38), \mathrm{n}=(\%)\end{array}$ & $\begin{array}{c}\text { II group } \\
\text { Learners with autistic } \\
\text { spectrum disorder } \\
(\mathrm{n}=44), \mathrm{n}=(\%)\end{array}$ & $\begin{array}{c}\text { III group } \\
\text { Learners with Attention } \\
\text { Deficit Hyperactivity } \\
\text { Disorder } \\
(n=29), n=(\%)\end{array}$ \\
\hline Being independent in: & & & \\
\hline $\begin{array}{l}\text { Communicating with } \\
\text { classmates and the } \\
\text { teacher }\end{array}$ & $15(40 \%)$ & $12(27 \%)$ & $14(48 \%)$ \\
\hline $\begin{array}{l}\text { Asking for help if } \\
\text { needed, express } \\
\text { wishes }\end{array}$ & $18(49 \%)$ & $9(20 \%)$ & $10(34 \%)$ \\
\hline $\begin{array}{l}\text { Participating in } \\
\text { games, out-of-school } \\
\text { events }\end{array}$ & $5(13 \%)$ & $10(23 \%)$ & $11(38 \%)$ \\
\hline
\end{tabular}


Learners with physical dysfunction and with musculoskeletal disorders (65\%) had major difficulties in organizing their free time in the middle of the classes, participating in play activities or in excursions. These problems were much more significant especially for the learners in a wheelchair, having walking and posture difficulties, they felt isolated from their classmates and did not take part in active games. While assessing the social communication skills of learners with autism, it became clear that they (50\%) experienced difficulty in communicating with their classmates and teachers, and most were unable to express their opinions, answer questions, participate in the non-educational process, and ask for help when needed.

The results of the assessment of the above-mentioned abilities among the learners with ADHA showed that this group had significant difficulties in engaging in social interactions and play activities. During communication with classmates, they behaved negatively, aggressively or hyperactively. Despite the fact that many of them (48\%) were able to communicate with their classmates, they nevertheless showed restless, persistent behavior in response to remarks made by teachers. The others (41\%) had difficulty participating in play activities, often showed verbal or non-verbal aggression during the game, they were hyperactive and had a hard time waiting for their turn. And only $34 \%$ were able to express their wishes, opinions and ask for help.

In school environment children based on their social skills engage and communicate with one another that may include both verbal and non-verbal communication, such as the use of language, personal appearance, body language and facial expressions (Durlak, Dymnicki, Taylor, 2011). Thus, current research intended to evaluate the learners' social and communication skills, as communication was a collaboration of two or more people aimed at getting mutual understanding, establishing a relationship, exchanging information that mutually influences self-expression, emotional sphere, well-being (Andreeva, 2004). Indeed, adequate social skills are considered to be an essential facet of a person's personality and behavior (McKown, Gumbiner, Russo, 2009). Occupational therapy trainings are aimed at improving skills to create proficiency for human development and to indigenize appropriate behaviors that provide to deal with the difficulties of daily life in children and adolescents and promote health, and well-being. Especially, where the health issues are associated with behaviors that cause inadequacy to cope with personal and social challenges powerfully, developing psychosocial competence may be an important way to contribute to well-being and health (O’Conner, De Feyter, Carr, 2017).

\section{Having self-care performance challenges at school.}


Because, in addition to the educational process, the learners carry out also self-care activities at school, current research has assessed their participation problems in self-care activities at school. The study focused also on environmental conditions to find out possible assisting ways for facilitation and enlarge the learners' performance and their eating, using bathroom/toilet, changing clothes (put on/off) activities and different tasks performance in school environment were assessed.

According to the data analysis, the majority of learners with physical dysfunction and musculoskeletal disorders (62\%) were unable to perform self-care activities and constantly needed support and assistance. It should be noted that $84 \%$ of the participants could not use the bathroom/toilet on their own, as there was a lack of appropriate skills and the inconvenience of environmental conditions at schools. Only a small portion of the respondents (13\%) were able to change their clothes on their own, take off their clothes (coat, jacket), the rest (32\%) needed support, and about $54 \%$ could not perform the activities on their own. Because at school learners with SEN need to carry out self-care and perform daily activities not only the development of individual abilities was essential, but also appropriate and supportive environmental conditions need to be available (Law, et. al, 1999).

The results of the study showed that self-care activity performance level was relatively higher among the learners with autistic spectrum disorder (48\%) and learners with ADHD $(69 \%)$, as in general they did not have physical and mobility problems and the environmental conditions were appropriate for them. However, due to cognitive, behavioural and emotional problems that experienced learners with autistic spectrum disorder and ADHD, their independent participation in self-care activities was also limited. Most learners with autism (36\%), and learners with ADHD (31\%) needed help for self-care activities at school. The respondents were not able to use the bathroom/toilet on their own due to spatial orientation, hyperactivity, and other behavioural problems (Figure 4).

\section{Figure 4.}

\section{Participation in self-care activities of learners with autistic spectrum disorder.}

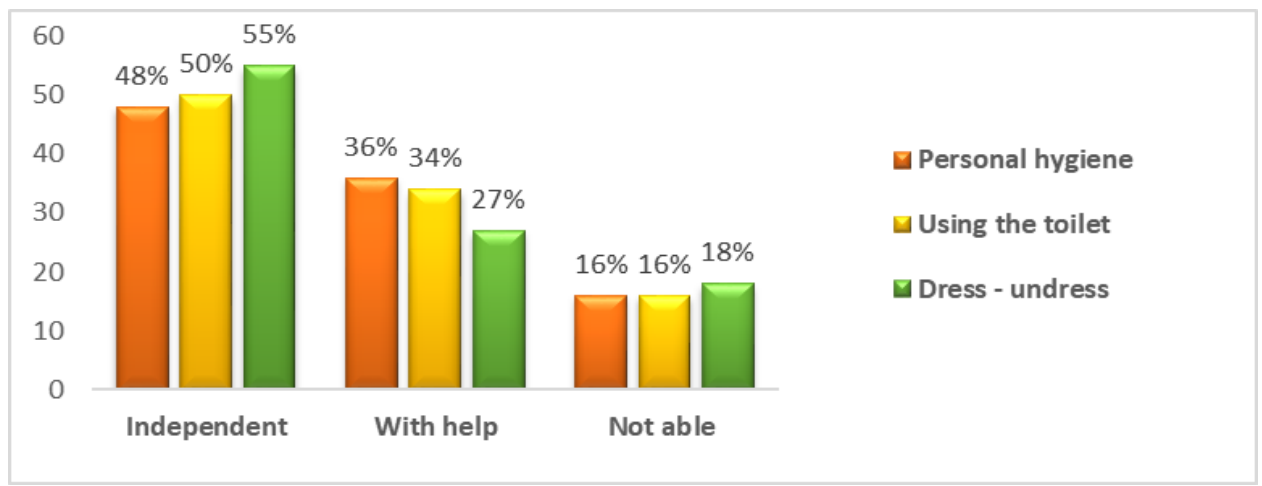


In summary, the research results stated that the independent participation of the learners with SEN in inclusive schools was still limited; there was a need for Occupational Therapy intervention to advance individual skill training and carry out environmental modification for overcoming the learners' participation restriction in educational and non-educational activities, to develop an appropriate program, and provide permanent support and assistance.

\section{CONCLUSION}

This study explored the participation restrictions of the learners with SEN in inclusive schools in order to frame and outline possible Occupational Therapy intervention approaches and main directions in Armenia. In the schools implementing inclusive education, there were still significant difficulties and limitations in the effectiveness of organizing the educational process in all directions. Still, there was a need for conducting individual assistance and developing skills of the learners with SEN for facilitating their functional mobility and participation in school activities, particularly in educational and self-care activities. To increase the effectiveness of participation in school activities of these learners not only individual skills and abilities needed to be advanced but also school environment had to be adapted and adjusted in accordance with their special needs. The main focus of school-based Occupational Therapy was ensuring and organizing an effective educational process while increasing the involvement of learners with SEN in educational and non-educational activities, enhancing their independence and providing a supportive and accessible educational environment.

\section{REFERENCE}

1. Agran, M., Blanchard, C., Wehmeyer, M. (2000). Promoting transition goals and selfdetermination through student-directed learning: The Self-Determined Learning Model of Instruction. Education and Training in Mental Retardation and Developmental Disabilities, 35, pp. 351-364.

2. Ainscow, M. (1999). Understanding the development of inclusive schools. London: Falmer.

3. American Occupational Therapy Association. (2014). Occupational therapy practice framework: domain and process (3rd ed.). American Journal of Occupational Therapy, 68(Suppl.1), S1-S48. Doi: https://doi.org/10.5014/ajot.2014.682006.

4. Andreeva, G. (2004). Psychology of social cognition. Tutorial. Art. 94-102. 
5. Armstrong, D. (2012). Examining the evidence for interventions with children with developmental coordination disorder. British Journal of Occupational Therapy, 75(12), pp. 532-540.

6. Bazyk, S. and Cahill, S. (2015). "School-based occupational therapy," in Occupational Therapy for Children and Adolescents, J. Case-Smith and J. O’Brien, Eds., pp. 664703.

7. Bernal, J. (2009). Creating an Inclusive Society: Practical Strategies to Promote Social Integration, pp 8-11.

8. Case-Smith, J. (2015). Foundations and practice models for occupational therapy with children. Occupational therapy for children and adolescents, 7th ed., pp. 27-64.

9. Case-Smith, J., Holland, T., Lane, A., \& White, S. (2012). Effect of a co-teaching handwriting program for first graders: One-group pretest-posttest design. American Journal of Occupational Therapy, 66, 396-405. http://dx. doi.org/10.5014/ajot.2012.004333

10. Case-Smith, J., Weaver, L., \& Holland, T. (2014). Effects of a classroom-embedded occupational therapist-teacher handwriting program for first-grade students. American Journal of Occupational Therapy, 68, 690-698. http://dx. doi.org/10.5014/ajot.2014.011585

11. Cohn, E., and Lew, C. (2010). Occupational therapy's perspective on the use of environments and contexts to support health and participation in occupations. American Journal of OT, 64(Suppl.), pp. 57-69.

12. Durlak, J., Dymnicki, A., Taylor, R. (2011). The impact of enhancing students' social and emotional learning: A meta-analysis of school-based universal interventions. Child Development 82(1): 405-432.

13. Fisher, A., and Jones, K. (2014). Assessment of Motor and Process Skills. Vol. 2: User manual (8th ed.).

14. Harutyunyan, M. (2014). "The experience of schools implementing inclusive education in the Republic of Armenia, the role of the teacher the summary of the existing problems in the system", Problems of Special Education, Scientific-Methodological Journal, pp. 49-53.

15. Harutyunyan, Z., Hovyan, G. (2013). "Multidisciplinary team work as a precondition for effective organization of inclusive education", Pedagogy Scientific-Methodological Journal, 7, pp. 21-25.

16. Harutyunyan, M., Hovyan, G., \& Harutyunyan, Z. (2018). "Pedagogical and rehabilitation support as a prerequisite for organizing effective inclusive education Priorities of Pedagogy and Modern Education", Collection of articles of the International Scientific and Practical Conference, 05.03.2018. Penza ICNS "Science and Education", art. 300-303.

17. Haug, P. (2017). "Understanding inclusive education: ideals and reality," Scandinavian Journal of Disability Research, vol. 19, no. 3, pp. 206-217. 
18. Hemmingsson, H., Borell, L., Gustavsson, A. (2003). Participation in school: School assistants creating opportunities and obstacles for pupils with disabilities. Occupation, Participation and Health, 23 (3), pp. 88-98.

19. Howe, T., Roston, K., Sheu, C., \& Hinojosa, J. (2013). Assessing handwriting intervention effectiveness in elementary school students: A two-group controlled study. American Journal of Occupational Therapy, 67, 19-26. Doi: http://dx.doi.org/10.5014/ajot.2013.005470

20. Hoy, M., Egan, M., \& Feder, K. (2011). A systematic review of interventions to improve handwriting. Canadian Journal of Occupational Therapy, 78, 13-25. Doi: http://dx.doi.org/10.2182/cjot.2011.78.1.3

21. Kardos, M., Prudhomme White, B. (2005). The role of the school-based occupational therapist in secondary education transition planning: Pilot survey study. American Journal of OT 59(2), pp. 173-180.

22. Law, M. (2002). "Participation in the occupations of everyday life," American Journal of Occupational Therapy, vol. 56, no. 6, pp. 640-649.

23. Law, M., Haight, M., Willms, D. and et. al. (1999). Environmental factors affecting the occupations of children with physical disabilities, Journal of Occupational Science, Vol. 6, pp. 102-110.

24. Luria A., and Vygotski, L. (1965). The problem of localization of functions. Neuropsychology- N5.

25. Mackay, N., McCluskey, A., \& Mayes, R. (2010). The Log Handwriting Program improved children's writing legibility: A pretest-posttest study. American Journal of Occupational Therapy, 64, 30-36. Doi: http://dx.doi.org/10.5014/ajot.64.1.30

26. Mann, D., et al. (2015). Executive functioning: Relationship with high school student role performance. Open Journal of Occupational Therapy, 3(4).

27. McKown, C, Gumbiner, L., Russo, N. (2009). Social-emotional learning skill, selfregulation, and social competence in typically developing and clinic-referred children. Journal of Clinical Child \& Adolescent Psychology 38(6): 858-871.

28. "Occupational Therapy School Skills Assessment": Doi: www.therapyfunzone.net/blog/wp-content/uploads/2010/09/Microsoft-Word-OTschool-skills-assessment.pdf\#new_tab

29. O’Conner, R., De Feyter, J., Carr, A. (2017). A review of the literature on social and emotional learning for students ages 3-8: Characteristics of effective social and emotional learning programs (Part 1 of 4). Doi: https://ies.ed.gov/ncee/edlabs/projects/project.asp?projectID $=443$

30. Polichino, J. E. (2001). An education-based reasoning model to support best practices for school-based OT under IDEA 97. School System Special Interest Section Quarterly, $8(2), 1-4,35$.

31. Reid, D., Chiu, T., Sinclair, G., Wehrmann, S., and Naseer, Z. (2006). Outcomes of an occupational therapy school-based consultation service for students with fine motor difficulties. Canadian Journal of Occupational Therapy, 73, 2006, pp. 215-224. 
32. Rens, L., and Joosten, A. (2014). Investigating the experiences in a school-based occupational therapy program to inform community-based pediatric occupational therapy practice. American Journal of Occupational Therapy, 61(3), pp. 148-158.

33. Resolution of Government of the Republic of Armenia. (2016). "On approving the action plan and schedule for the implementation of the general inclusive education system.", No. 6, February 18,

34. Saratikyan, L. (2013). "Problems of introduction of inclusive education system, training of specialists", Problems of pedagogy and psychology. Scientific journal of the interuniversity consortium (3), pp. 44-51.

35. Sayers, B. R. (2008). "Collaboration in school settings: a critical appraisal of the topic," Journal of Occupational Therapy, Schools, \& Early Intervention, vol. 1, no. 2, pp. 170-179.

36. Schneck, C., and Amundson, S. (2010). Prewriting and handwriting skills. In J. CaseSmith (Ed.), Occupational therapy for children (6th ed.). pp. 555-580.

37. Starczewska, A., Hodkinson, A., and Adams, G. (2012). Conceptions of inclusion and inclusive education: A critical examination of the perspectives and practices of teachers in Poland. Journal of Research in Special Educational Needs, 12 (3), pp. 162-169.

38. United Nations, "UN Convention on the Rights of Persons with Disabilities," (2006). Doi: www.un.org/disabilities/documents/convention/convention_accessible_pdf.pdf.

39. UNESCO. (1994). "The Salamanca statement and framework for action on special needs education". Doi: www.unesco.org/education/pdf/SALAMA_E.PDF.

40. Universal Declaration of Human Rights, United Nations, (1948).

41. World Federation of Occupational Therapy. (2016). "Position statement. Occupational therapy services in school-based practice for children and youth". Doi:www.wfot.org/AboutUs/PositionStatements.aspx.

42. Yadov, V. (2007). Sociological Research: Methodology Program Methods, p. 102 105. 